\title{
Virtual reality full immersion techniques for enhancing workers performance
}

CASAS, L. A. A.

Professor DAIE/FIPS/UNSA. Arequipa - Perú, M. Eng. Produção, Doutorando PPGEP/UFSC, Brazil

casas@mbox1.ufsc.br

BRIDI, $V$. $L$.

Medicine, Mestranda PPGEP/UFSC, Brazil

bridi@cce.ufsc.br

FIALHO, F. A. P.

Professor PPGEP/UFSC, Dr. Eng. Produção

Departamento de Expressão Gráfica -CCE/EGR, UFSC -

Florianópolis-SC-CEP:88040-900, Brazil

ffialho@matrix.com.br

\begin{abstract}
The aim of this paper is to analyze the potential use of computers as educational tools for enriching organizations educational programs with modern learning environments. The theoretical basis of the article relies in Human Cognition, mainly taking its biological support into consideration. An investigation was performed, pointing out properties and advantages of Virtual Reality Immersion and its contribution for knowledge construction. The idea is that continuous education activities are needed and that modern technologies can support it. Finally, we establish our conclusions and suggestions for future developments in the field.
\end{abstract}

\section{Keywords}

Virtual Enterprise, Computer Assisted Learning Environments, Virtual Reality, Knowledge Construction by Immersion in Virtual Reality. 


\section{INTRODUCTION}

The emergence of new technologies, the fast changing economical and juridical variables, caused by countries integration in multinational organizations, together with changes occurring in the social tissue, happening nowadays, make obsolete the knowledge acquired in the school or university, turning then insufficient to face new situations occurring in work or daily life. (Fernandez, Lopez, Kumpel, Villa, 1992, p. 333). The natural obsolescence, due to this fast changing technology added to the forgiveness of acquired knowledge, due to automation, implies in a reduction of the overall company workforce efficiency. The educational system, responsible for individual formation, is not prepared to follow the rhythm of these mutations occurring both in technology as in industrial processes.

The new organization is leading to a new social order, where only qualified workers will have a place. The instruction or training performed as it was done in mass production systems are not sufficient for companies working under a Lean Production System paradigm. At the same time, the increasing diversification of the work force, requires new capacity approaches, where the new paradigm is learn while working (Borges, Borges, Baranauskas, 1995, p. 154). The same argumentation is valid for Learning to Learn Organizations.

The educational segment is growing faster than any other, inside industries, as an answer to these challenges, in order to make the work force follow this flow (Reinhardt, 1995). It is an organization need to prepare their employees for a more active participation in the decision making process.

New approaches for employees training that results in something interesting, stimulating, able to supply the answers asked under this new enterprise point of view, are requested. These new approaches must be designed to expand employees vision, beyond its routine work limits. In order to succeed in attaining a global participation in the work, questions like how to interpret and to produce an overall optimization of the processes, are a challenge whose answer can be found in training techniques, mediated by the use of computers.

\section{COMPUTERS AS AN EDUCATION AID}

Literature on Computer Aided Instruction (CAI) presents three generations of educational philosophies, prior to the advent of virtual reality, the fourth. The first generation was based on the behavioral approach (Winn, 1993, p. 5), that is:

- Student behavior can be foreseen if one has sufficient knowledge about the intended instruction results, the employed methods and the training conditions (Reigeluth, 1983);

- Students knowledge and skills that are beyond the teachers understanding, can be standardized and reduced, using appropriated analytical techniques, toward atomic components, in which domain one can work it out to obtain a desired behavior (Landa, 1983);

- The prescriptive instructional theory is sufficiently reliable to affirm that the design procedures guarantee that the instruction, developed by such a systematic application, will be effective, without the need of professors or designers (Gagne, Dick, 1983).

These argumentations were strongly refuted by Streibel (1991), and Winn (1990, 1993). In spite of this, the idea of a computer assisted instruction developed in accordance with this philosophy is still followed. 
The second CAI generation states that design must focus on how to present the information to the students and not on the content of the presentation itself (Flemming \& Levie, apud Winn, 1993, p.5). The emphasis on the processing aspects of instructional messages, resulted from psychologists perception that the behaviorist theory is incomplete. Cognitive theories about human learning are more satisfactory for models 'design orientated' (Bonner (1988); Campagne, Klopfer, Gunstone (1982); DiVesta, Rieber (1987); Tennyson, Rasch (1988), Winn (1990)).

The emergence of the second generation implied in a significant impulse on CAI systems. Since Gardner (1983, 1993) considerations that two students are not similar in its psychological conditions, and Cronbach, Snow (1977) considerations that these individual differences are important enough, that designers are faced with the prescription of developing different instructional methods considering not only students aptitudes but also, as signaled by Tobias $(1976,1989)$, skills.

The third generation of CAI systems comes from the belief that, although men machine iteration nature is a determinant of the learning process, with an importance equal or greater than the content itself, the way the information is presented is also meaningful. This orientation is strongly based on cognitive sciences. Truly, cognitive theories, such as ACT (Anderson apud Guine, 1991, p. 253), are being used as a support for developing intelligent tutors, highly interactive (Wenger, 1987). One of the recent and strongest approaches is given by Merrill (1991, 1993), "Instructional Transaction Theory", based on the idea that all learning results from transactions between students and software.

An approach for CAI that bets on the understanding on how the student interacts with learning resources is just a first step for the fourth generation in which the central point is the belief that knowledge is built by the students themselves and not supplied by a third person. Bartlett (1932) was the first to propose, based on Jean Piaget, that learning occurs when an individual build "schemes" representing some particular aspect of the world he lives in. Neisser (1976) suggests that schemes are active structures that drives the way people search for information in their surroundings. Recent theories about knowledge construction, like the work of Spiro (1991) "Cognitive Complexity Theory", and Bransford (1990) "Anchored Instruction", are based in cognitive theories.

Ideas such as the metaphor linking 'human mind working' and computers, and that cognition consists of symbolic manipulation (Boden, 1988; Jackendoff, 1987; Johnson-Laird, 1988; and Pylyshym, 1984) are common in Cognitive Sciences. Marr (1982), in his seminal work on vision, suggests that the mind is too complex to be understood and that the only possible approach consists in explain cognition as computations based on mathematical models related to a chosen cognitive model.

The 'human mind' - computer metaphor, results in the belief that cognition is structure and symbolic dependent. Computer interfaces limit students experiments to "third person ones". The corollary is that first person psychological activity, non reflexive, non symbolic, that occurs when the person interacts directly with real or virtual worlds, have no place in Cognitive Sciences Theories (Winn, 1993, p.7). This is a fatal omission, as pointed out by constructivists and critics of cognitive sciences (Dreyfus (1972); Edelman (1992), Searle (1992)).

Constructivism describes the ways of knowledge, the process of cognitive structures and functions construction, as well as the related learning processes. While these considerations do not form an unified theory, three hypothesis about knowledge construction give support for learning experiments and Virtual Reality applications. 
- Maturana and Varela (1972) work, together with Thompson and Rosch (1991) developments, play a particular influence on some constructivists like Cunningham (1993). Maturana and Varela propose that living beings, including humans, do not take information from the outside but react to perturbations occurring in the environment through adaptations of existing internal structures. Interactions with the environment do not add directly to the organism physical structures. Interaction promotes indirect quantitative and qualitative exchanges in symbols and mental structures. The skill of detecting perturbations and the class of structural change they produce are determined by the species evolution experience (Maturana, Varela, 1992, p. 69) and the individual adaptations, or ontogenesys (Maturana, Varela, 1992, p. 67). The interpretation and representation (symbolization) of the world depends on structural adaptations due to the interaction of a symbolic and real world with these perturbations. In accordance with Maturana (1970), learning is not a process of accumulating media representations. It is a continuous behavior transformation process.

- Construction in each human being is unique. Nagel (1974) pointed out that even being able of building a description of some other experiences, talking in third person, we will never be able to know how the other feels. This means that the experience of one entity with the world of anybody else can only be a third person world description experience (Winn, 1993, p. 7).

- These two previous suppositions guides contructivism toward a solipsism. If we are closed in terms of information (Maturana, Varela, 1992, p. 109) and if the objective world is not a pattern, so we are condemned to the impossibility of communicating with others.

Nevertheless, communication turns possible by what Maturana and Varela (1992, p. 49) call "structured coupling". Organisms of similar species basically share similar apparatus for detecting and adapting to perturbations. Moreover they inhabit similar environments where there is a trend of finding similar perturbations. As a result, the story of their structural adaptations, can be similar. Their structures are coupled. That is why we can communicate with other human beings.

In accordance with Vigotsky (1978), to make communication possible, we have to have an approximation about the meaning of the symbols given by others. Negotiations between group members about meanings can only result in temporary agreements. Due to this fact, in accordance with McMahom \& O'Neil (1993), the constructivist praxis frequently insist in presenting learning opportunities that demands the students to work in groups searching for a general agreement about meanings.

The environment where the students can build knowledge must be created. Proposals of environmental learning construction recommends instruction (Brown, Collins \& Duguid, (1989); Brown \& Duguid (1993); Lave \& Wenger (1991)) and reflexive praxis (Schon (1987)) as the best method to allow students knowledge construction departing from "authentic" activities. Kozma (1991) states that technology is reaching a state of the art where it is possible to create artificial learning environments that could not have being created following traditional strategies and that this quality is the one that allows the development of superior pedagogical methods.

The coming "fourth generation" of ICAI (I for intelligence) is based on constructivist learning theories. 
Each individual learning mode is a combination of how he perceives, organizes, and processes information. Although it is possible to give different names for the several learning styles, one can, in a simple way, to split then in two main learning categories (Guillon, Mirshauka, 1995, p. 20).

- Modality, defined as the way we understand the information.

- Cerebral dominance, defined as how we organize and process information.

Among learning modalities we quote (Guillon, Mirshauka, 1995, p. 21) visual, audio, and Kynestesics. In situations where we know the visual, audio, and kynestesics characteristics of a cognoscente individual, it is more simple to "tune" the learning process to the modality more adequate. This process could be realized through the use of Information Technologies, using resources like multimedia, hypertext, hypermedia, virtual reality, and telematic, that can give teaching flexibility, personalization, interactivety and quality.

Multimedia. The use of texts, graphs, sounds, images, animation and simulation, interactively combined to provoke a previously determined effect.

Hypertext use, allowing to situate different topics that are inter related one with the others in several levels, turns possible to personalize the learning process letting the student find his rhythm, level and style.

Hypermedia: A good hypertext combined with multimedia, offers what Nielsen calls "hypermedia".

Virtual Reality is defined by (Rios, 1994, p. 1), as "the environment and men sensorial mechanisms computer simulation, that supply users with the sensation of immersion, providing also the ability of interacting with artificial environments".

\section{VIRTUAL REALITY}

Virtual reality is one of the newest computer sciences branches. There are several terms related to the same concept, like "Synthetic Reality" and "Cyberspace".

There are several definitions for Virtual Reality. One can take Rios $(1994$, p. 1) definition, others can say that "Virtual Reality is just a mathematical model that describes some 3D space". Virtual Reality can be defined also as the way humans can visualize, manipulate and interact with computers and extremely complex data. For some people, Virtual Reality is any interactive simulation, for others virtual reality is only obtained when you are in a network and several people share their realities between themselves, like in virtual communities (BBS) and schemes MUD (Multi User Dungeon). There are still researchers that limit the term virtual reality to the use of_sophisticated equipments, like Head Mount Devices, that is, 3D synthetic realities. In accordance with other investigators, through virtual reality it's possible to experience tangible models of places and things, where tangible means that the model can be directly perceived by the sensorial apparatus and not through language or mathematical models.

Virtual Reality is a step beyond computer simulation, dealing with interactions occurring in real time, a dynamic simulation.

In accordance with Rios $(994$, p. 2$)$, the characteristics of a virtual reality system, that discriminate it from other information systems, are: 
- Immersion: property that provides the user with the sensation of being inside a 3D world.

- Existence of a observation point or reference that allows the determination of the user position and situation inside the artificial or virtual world.

- Navigation: property that allows the user to change his observation point.

- Manipulation: characteristic that makes possible interaction and transformation of the virtual environment.

The elements present in any Virtual Reality system are:

- Interaction: allowing the explorer to control the system. Absence of interaction reduces the system to a movie or video. To allow interaction several interfaces, from keyboards, data gloves, and special dresses, can be used.

- Perception: comes to be the most important factor. Some systems are addressed directly to the senses (visual, tactile, ear); other systems try to reach the mind directly, avoiding external sensorial interfaces, and still others, more humble, recurs to the imagination strength to allow human beings to live a virtual reality experience.

- Simulation: simulated worlds do not have, necessarily to adapt themselves to natural physical laws. This is the characteristic that makes virtual reality applicable to any human activity. We accept that some applications are more proper than others. Virtual Reality is more than a simple simulation, offering interaction with the model, allowing users presence inside the virtual world. Through this capability it is possible to realize tasks inside a remote world, or a computer created one, or a combination of both.

In accordance with W. Robinnett the models to be used in Virtual Reality systems can be grouped in the following categories:

- Models captured by scanners, digitizer apparatus, transferring elements from the real world; telepresence systems using video camera (one for each eye), to explore the real world from a remote place, sound records for each ear registering a distant world audio model.

- Calculated models, that are mathematically computed, allowing a posterior buildingvisualizing-manipulation, which are generally used in complex or abstract models, like air flux models in a air turbine or the lava flow of a volcano in a valley.

- Models build for artists, that are generally generated in CAD systems, created with complete coordinated structures. These models can be based on fictitious or real spaces. A cuisine of the future or a spatial landscape, for example.

- Models edited from a combination of contents captured by scanners, calculated or created by artists.

In accordance with its elements, a Virtual Reality can be classified in the following categories:

- Desktop systems of Virtual Reality: Comprehends all kind of applications that shows 2D or 3D images in the computer video, instead of projecting then in a Head Mounted Device (HMD). Due to the fact that they represent 3D worlds, the explorers can navigate in any direction inside these worlds. Characteristic examples of these environments are computer flying simulators. Shortly, Desktrop virtual reality shows 3D worlds through 2D screens. Some of then incorporate complex interfaces like data gloves, control commands, customized cabins, but all of then will present the above mentioned characteristic (3D in 2D). 
- Immersion Systems: Those are the ones that submerge or introduce the explorer in a close relation with the virtual environment they are dealing, through the use of visual systems like HMD, gestures and movements following devices, like sound elements processing systems, giving the participant the sensation of a very close relation with the artificial environment and, at the same time, isolating then from the real one.

Computer user interface elimination is a needed condition for virtual reality immersion. The participant "dresses the computer". He is part of the data. As a result, applicants can interact with the virtual world, which can include some simulation or aspects of the real world, some abstraction instance that could be only accessible as numerical data, or the creation of some fantasy from imagination, like we do in our daydreamings. This is a great advantage over natural interactions. (Winn, 1993 : p. 2).

These 3D immersion worlds can be obtained through the creation and sending almost similar images to the eyes, which provides depth, perspective and dimension sensation. What each player sees and experiences must be computed for each eye, for each detected movement, in order to present a new adequate sound or image position.

Immersion virtual reality systems allow the navigator to go to any place inside de assembled structure, to cross walls, float, levitate toward the sky, penetrate the earth core, etc.

- Second person VR: The immersion difference arising from being in a second person systems (or unencumbered systems) involves real time perception and answers to actions of others participating in the experience, which can be performed by the use of gloves, HMD's, conducting wires or any other interface.

In spite of this, in second person systems, the navigator knows that he is inside the virtual world because he can see himself inside the scene, that is, he is part of it. To allow this feature his image is added to the environment image (chroma-keyed) in order to build the complete image the explorer have access to. Through a contour detecting software it is possible to realize manipulations inside the scene, which can be visualized in the video monitor. More then imitating real world sensations, a second person system changes the rules, based in the old notion that "we need to see in order to believe", inducing a being present sensation.

- Telepresence systems. Immersion systems simulate real world perception. The travelers coming from the real world knows that they are inside because the sounds of the virtual world, and head movements, are answered in a similar way it would be done in a real environment.

\section{LEARNING BY KNOWLEDGE CONSTRUCTION}

The use of technology to improve the quality of constructivist learning environments, nowadays, is centered in the creation of computational tools and virtual representations that students can manipulate (Dede, 1995, p. 1). Perkins constructivist approach (1991), includes: Data banks, construction kits, and administration tasks.

Interpreting apprentices experience on refining their mental models by the use of these tools, we conclude that computational tools, designed for aiding students memory and intelligence associated skills, are available to teachers. Parallel to these applications, transitional objects (similar to the Logo turtles) are used to facilitate the transference of abstract symbols obtained from personal experience (Papert (1988); Fosnot (1992)). 
Constructivist knowledge, improved by technology, focus, currently, in how representations and applications can mediate the interactions between apprentices and natural or social phenomena.

The key for the compatibility between Virtual Reality and constructivism arises from the immersion notion. First hand experience considers the processing of our world activities and the learning resulting from these processing. First hand experience occurs when our interaction with the worlds do not enroll symbol use or conscious reflection.

In accordance with constructivist theory, knowledge building emerges exactly from these first person experiments, the ones that can never be completely shared. Immersion experiences allow this kind of experiences by the elimination of user computer interfaces (Winn, 1993, p. 15). In other words, immersion in a virtual world allows us a knowledge building derived from direct experimentation and not through a description of another person experience.

Any kind of learning is mediated by a system of symbols: a text, some spoken language or computer. It is a reflection on others experiments. Any specification we use in a symbolic system to communicate about the world we build for another person will never allow this other person to know this world as much as we do. Constructivism theory describes how the worlds of the first person come to be internalized, arguing that any imposition of symbolic representations requires negotiation (Flores, Winograd, 1989, p. 79).

Virtual Reality Immersion provides a class of interactions that is similar to our natural interaction with real world objects. If cognition is non symbolic, and learning is associated with action, through interaction with the virtual world, knowledge can be build. Immersion, or the sensation of being present, of being inside and surrounded by the virtual environment, is analyzed in terms of individual differences: motivations, environment visual characteristics, interactivety, and the role of the several sensations in the assembling of a Gestalt. (Psotka, 1996, P. 1).

Papert (1991) and his colleagues use the world "constructionism" to describe knowledge building arising through physical interaction with world objects. Immersion provides these physical and perceptual interactions.

Due to the fact that the virtual environment is computed from collected data, three classes of learning constructions experiences that are not possible in real world but that show a high interest for education, are possible: These concepts are called: "Dimension", "Transduction", and "Reification" (Winn, 1993, p. 16).

- In real world an object seems bigger when I get close and diminishes when I move apart. In spite of this, there are limits. There is a point where I can not get closer and this point signals the maximum apparent dimension of an object. In a similar way there is a point where the object disappears. In a virtual world I can get as close as I wish or be so far away and still see the object. Before colliding with a virtual wall, for example, I can get approximations in such a way that details, smaller and smaller of the wall material, can be unveiled. I can appreciate the cellular structure of a wood panel and, equally, travel through the atoms that constitute its molecules. In the other extreme, I can go from the wall to the house, and then to the city, the planet, and so on, without violating the four immersion conditions. (Like in Cosmic Zomm, produced by the National Film Board of Canada, that follows these ideas, going beyond what we are describing here).

The advantages of providing these dimensions changing properties for education are meaningful. 
It is possible, for the student, to penetrate an atom, inspect it, and change the orbits of their electrons, altering atoms valence and their combination capacity to form other molecules. It is possible also, for the students, to get the notion of the relative distances between the planets, just flying from one to another.

- Transducers are similar to earphones and are used in Virtual Reality hardware to present information and to convert participants behavior in commands to be interpreted by a software. Transducers are devices that transform information not accessible to our senses in other forms.

- Changes in dimensions and transduction provide a first person experience impossible to be obtained in other learning environments. Some of these experiments emerge from the simulation of events or aspects of real objects. Others come from the representation of abstractions, that can only be perceived as non physical objects or events, like algebraic equations, or the dynamic opening of a flower. Reification is the process of creating these forms. Reification contrasts with simulation. In simulation, the virtual world contain facsimiles of real objects with their behavior.

\section{PROBLEMS RELATED TO AN OPEN VIRTUAL IMMERSION}

Immersion characteristics were analyzed in a U.S. Army Research Institute research, through questionnaires designed to access individual susceptibilities for immersion and how deep was this experience to the participants.

In the research reported by Psotka (1996), the questions were carefully build to cover the cognitive factors mentioned in the literature as meaningful for virtual reality environments. A five point scale of categorical answers was used. Two psychological factors considered as dominants for predicting immersion deepness were: the imagination needed for accepting another reality (a living imaginary turns the participation integral and satisfactory) and the concentration, attention, and autocontrol needed to exclude real world distraction effects.

The extension of the visual field in a HMD, the precision of the egocentric localization, audio precise information (synchronized with visual changes like rotations, affirmation head movements, or accelerations), are determinant factors of an in depth immersion. A "cognitive tracking" paradigm was used to get visual-vestibular interactions. The precise synchronization of the head spatial movements and the changes in visual perspective result in a deeper immersion, even with an imprecise coupling between head movement and changes in the visual presentation (Psotka, 1996: p. 1).

Cognitive factors were grouped in two categories: Immersion susceptibility and quality.

- Susceptibility depends on imagination (dreams, a gift for replacing old beliefs), a living imaginary (dreaming, previous expectations about virtual reality environments), concentration and attention (attention filtering, cognitive conflict by two recursive immersions, spatial navigation), and self control (active participation and catharsis).

- Quality depends on the environmental resources provided by the virtual reality immersion (object persistence, sensorial perfection, interactivety, environment realism, delays, visual field, precise localization of the ego center or corporal image, pleasure and satisfaction with the new experience), distractions due to the real environment (noise, tactile presence, tiredness, irritation with the equipment (size or restrictions), similarity between real and virtual world), psychological effects (simulator disturbances, disorientation after immersion), and other effects (preference for a lonely immersion, surprise when the HMD is removed). 
Movements in the virtual environment, at the present stage of technology, can originate several errors (an extremely slow answer, failures). The main causes of movement errors are: imprecise scenery for the inter ocular distance, absence of convergence and accommodation signals, lack of good texture gradients for deepness and improperly designed models. They are easily perceived and remains a disturbance factor in several virtual reality applications.

Postka (1996: p. 3) reports that with a exhibition vision greater than $60^{\circ}$ (field of view, FOV), several individuals relate some level of discomfort although not mentioning nausea. In accordance with Wertheim (1993) and Wolpert (1990) the relationship between behavior and the study about self oriented emotions are strongly dependent on FOV. The most influent requirement for immersion is a solid coupling between head movement and visual exhibition. Data input delays in visual exhibition using HMD immersion results in a brisk interruption of spatial orientation and a poor immersion experience (Psotka, 1996)

Immersion can be understood as a dual phenomena; from one side it depends on subconscious skills and, from the other side it depend on our voluntary attention abilities that depends on self control, self consciousness, will, expectations, etc. Those two factors (implicit versus conscious immersion control) are captured by the found correlation that immersion is more complete in some one that is able to have colored dreams (Psotka, 1996a).As those two components interact is a mystery. The implicit and conscious components seem to perform different things without affecting, one the other, directly. These factors appear so briskly that they make themselves visible in all three sets of correlation: in the susceptibility factors, in the immersion factors, and in their intercorrelations. Implicit factors present a kind of dominance. If the delay between the iteration and the visual feedback of a movement perceived by a hand, in Virtual Reality, is to big, in such a way that there is no image filtering technique sufficient to reduce this delay; disturbance occurs. When the visual system indicates that the egocentre or corporal image is in a certain location but the kynestesic centers are in some near place, there is no way to integrate these two positions. It can be necessary a long time for the learning and adaptation processes to change the cognitive machinery (Psotka, 1996a).

Instead of supplying access to a greater cyberspace, the equipment used nowadays is still causing sensations like claustrophobic, nausea and confusion after the experiment (Psotka, 1996a)

\section{CONCLUSIONS}

When a baby is born, as stated by most psychologies (including psychogenetics), he is nothing more then a set of parts: hairs, skin, ... There is nothing one can call Ego, that is, nothing showing consciousness, that thinks about himself as "I". If there is not an 'I', we can not talk also about "Others". There is no interface between interior and exterior. In other words, there, in the origin, we have our so searched 'non interface', pure absence of differentiation, Jacques Lacan concept of "Real".

The first logical question is: How and when this "I-candidate" assumes his place as an individual? In psychoanalysis what we are discussing here is how we get the "I" form an image - Moi - that represents the individual for the Others - Je -. In other words, we are talking about an identification process that allows the subject to function as a being able to exchange information with mother, father, or simply, the Others. 
"There is a magic moment in this evolutive process that occurs when the baby looks at his own face in the mirror, recognizing himself as someone apart from the Real World. A symbolic interface that will mediate our external or internal interactions is then established'. The baby sees his image because her mother eyes (personification all the Others) sustains this knowledge. The baby sees himself through the eyes of her mother. His mother provokes the first Learning. A Learning about himself

The important thing is not the mother's eyes, but her strong desire, a "symbolic matrix" offered to the infans (Lacan, 1949: 87). The baby holds himself to this image to be the object of her mother desire. We have here a three personage representation. The reflected image, the subject, and the acting of a third person. Teaching is always a representation involving three persons at least: the student, the image this student has about himself, and the teacher.

What is there, reflected in the mirror, represents the individual for the others and even for the individual himself. But this image is not the individual. Jacques Lacan says that the I (moi) is constituted by the sacrifice of the Je (no translation at my possibilities). Anyway that is a natural tension between the 'Moi' and the 'Je' that provokes learning searching. In other words, we are condemned to lose our equilibrium and search for a new equilibrium state through learning.

The materialization of the perceptual and cognitive components of immersion seems to be a long and arduous task but, for sure, the results will compensate all the effort. In spite of this it is particularly satisfactory, nowadays, for training and educational proposals, because we already know that most of the cognitive representations assume the form of mental models, that are used for understanding complex systems. Virtual Reality promises to turn education and training in tools much more direct and effective than nowadays (Psotka, 1996b).

It is primordial to insist in a continuous education, open, flexible, personalized, allowing the individual to update and adequate his knowledge throughout all his professional life. The creation of distributed environments for a constructivist learning is a challenge. Research in this field is needed for the development of cooperative learning tools able to facilitate and motivate learning.

The development of intelligent didactic systems is complex demanding the support of knowledge coming from different fields.

A multidisciplinar team, including pedagogues, educational psychologists, specialists in the knowledge domain, technicians in computer graphics, programming, multimedia, virtual reality, project management, and others, are needed.

A sustainable industrial production will not be possible in organizations designed under some mechanical metaphor. Organizations are complex systems that can be modeled as higher order autopoietic living beings. Survival in the fast changing environment we are living in demands for a continuous adaptation. Immersion techniques seems to be the tool we need to enhance the chances of organizations survival, training and educating people to face the challenges of concurrence in a global economy.

Virtual Immersion introduces new resources for inter individual communications that deals with reality interpretation. In this paper we tried to outline the beginning of a long journey on how imagination power can be used for the collective creation of worlds able to improve learning. 


\section{BIBLIOGRAPHICAL REFERENCES}

BORGES, E. L., BORGES, M. A. F., BARANAUSKAS, M. C. C. (1995). Da simulação à criação de modelos - um contexto para a aprendizagem an empresa. Simpósio brasileiro de informática na educação, VI, Florianópolis - SC - Brasil, p. 154-165.

DEDE, C. (1995). The Evolution of Constructivist Environments: Immersion in Distributed, Virtual World. Http://www.virtual.amu.edu/pdf/constr.pdf

GUIN, M. D. (1991). Nécessité d'une spécification didactique des environnements informatiques d'apprentissage. Cachan. Les Editions de l'Ecole Normale Superieure de Cachan. 262 p.

GUILLON, A. B. B., MIRSHAWKA, V. (1994). Reeducação. Qualidade, produtividade e criatividade: caminho para a escola exelente do século XXI. Makron Books do Brasil. São Paulo.

FERNADEZ, M. KUMPEL, D. LOPEZ, A. De la Rica. VILLA, A. de la. (1992). Multimedia y pedagogía. Un binomio Actual. Congreso Computadoras Educación y Sociedad, República Dominicana.

FLORES, F., TERRY, W. (1989). Hacia la comprensión de la informática y la cognición. Barcelona. Editorial Hispano Europea. $266 \mathrm{p}$.

MATURANA, R. H., VARELA, G. F. (1992). El árbol del conocimiento. Santiago de Chile. Octava edición. Editorial Universitaria. $172 \mathrm{p}$.

MAZZONE, J. (1993). O sistema "enxuto" e a educação no Brasil. Em computadores $e$ conhecimento - Repensando a educação. J.A. Valente (ed), Gráfica Central da Unicamp. Campinas.

PSOTKA, J. (1996). Immersive training systems: immesion in virtual reality and training.: http://205.130.63.7/vrTraining.html

PSOTKA, J., DAVISON, S. (1996). Cognitive factors associated with immersion in virtual environments. http://205.130.63.7/vrfopub.htm

PSOTKA, J. (1996), Immersive tutoring system: virtual reality and education and training. http://205.130.63/its.html

REINHARDT, A. (1995). As novas formas de aprender. Byte, Março.

RIOS, H. F. (1994). Potencial de la Realidad Virtual: http: //lania.xalapa/ spanisch/publications /newleters /fall947index.html

WINN, W. (1993) A conceptual basis for educational aplications of virtual reality. http: //www.hitl.washington. edu/ projects/ education/ winn/winn-R-93-9.txt

WHITNEY-SMITH, E. (1996) Conversation, Education, Constructivism and Cybernetics. http: //www.well.com/ user/ elin/ edhom.htm 


\section{BIOGRAPHY}

Francisco A. P. Fialho graduated in 1973 in Electronic Engineering at Pontificia Universidade Católica do Rio de Janeiro, Brazil, where, in 1980, he specializes in Propagation of Electromagnetic Waves. He got his M. Eng. in Knowledge Engineering and his Dr. degree in Production Engineering (1994) at Santa Catarina Federal University. His special areas of interest are Virtual Immersion, Cognitive Ergonomics, Artificial Intelligence, Piaget, and Lacan. Dr. Fialho authored three books and has more than one hundred articles published in technical magazines and Congress Annals. 